ter, and the practitioner, who carefully prepares or superintends the preparation of the internal remedies he has prescribed. May it not be feared that if sanction be given by authority to such a false standard of respectability, the result may be to "elevate" the masses of the profession above their business, with no addition to that which is the true ground of respectability in their profession, viz., its usefulness and scientific character, but considerably to their own injury, and to that of the public at large?

Every medical man knows how much the success of his practice is dependent on the purity and proper preparation of the medicines he emplors; every medical man knows, too, that there is no department of trade in which the temptations to fraudulent adulteration are greater than in the sale of drugs and chemicals; and all those who have any practical acquaintance with such things, must be aware of the importance of bringing some scientific knowledge to the examination of them. It is, moreorer, probable, that the practice of fraudulent adulteration would increase If medicines were no longer likely to be submitted to the examination of men of scientific acquirements, but only to that of the retail druggists. I am well aware that among this class of tradesmen there are many persons of great experience and of thorough chemical and pharmaceutical knowledge, but it is too certain that the absence of any impediment in the way of the most ignorant person's opening shop as a chemist and druggist, together with the comparatively small capital required, have often thrown this business in to the hands of persons sadly ignorant of the nature and properties of the articles in which they deal.

Again: the importance of rigid accuracy in dispensing is selfevident. Prussic acid, for instance, is one of our valuable and most commonly used remedial agents. Would not many medical men feel better satisfied to prepare with their own hands a medicine containing this dangerous ingredient, than to leave it to the chance of being accurately measured by a chemist's apprentice, Where a few drops, more or less, may make the difference of life or death to his patient, and with, perhaps, a further risk of having Scheele's acid substituted for the weaker pharmacopoial preparation he has prescribed?

It may be added, as a further reason why no discredit should be thrown on that class of medical men who choose to dispense their own medicines, that a very large proportion of patients would be unable to pay the druggist in addition to remunerating their medical advisêr for his visits. The intrinsic value of most medicines is small; of the half-crown charged by the chemist for an eight-ounce mixture, perhaps three-fourths are profit, and very properly so, for it is but a fair return for his skill, and for the time and expense of an education that partakes, (or ought to partake, ) to a considerable extent, of a scientific character. If a necessity were imposed upon the community of obtaining their medicines only from chemists and druggists, it would seriously increase the expense of medical attendance, and would tend to drive the members of the profession into a disreputable copartnership with the retail druggists.

On these grounds, I hold that if the practice of dispensing their own medicines were surrendered by the mass of the profession, the result would be disastrous to themselves and to the community at large, and that so long as medical men do not assimilate themselves to retail trades, by charging for their pills and draughts instead of for their attendance, they detract nothing from the respectability of their professional character by furnishing to their patients the medicines they prescribe.

August 12th, 1845 . I am, Sir, your obedient servant,

\section{LUMINOUS BREATH.}

To the Editor of THE LANCET.

SrR,-I take the opportunity of penning a few lines in support of Dr. G. C. Watson's case of "Luminous Breath," as detailed in The Lancer of 4th January, 1845. When I stated the following circumstances to some of my friends, I was langhed at as a believer in "spontaneous combustion!" The case, although not to be called like Dr. Watson's, was something similar to it:-

One Hugh McCullum, a carpenter, an habitual drunlsard, had been suffering for some time, and was under my treatment, at different periods, for disease of the lungs, liver, and stomach. At about the commencement of August last he was suddenly seized with excessive cough, difficulty of breathing, and diarrhœa. The last I checked, to a certain extent, but the cough and dyspncea continued to his death. On the night of the $7 \mathrm{th}$, or $8 \mathrm{th}$, a black man, who was attending to him, called up the overseer of the estate, (an American quaker, of undoubted veracity,) telling him that the unfortunate McCullum was at his last gasp. The overseer arrived just in time to see him die, and observed, plainly, a spark of bright-red colour issue from his mouth, and disappear immediately. When he told me of it on the following day, I laughed at him, saying that he must have seen the reflection of the candle on a bubble of saliva. He replied that it could not have been so, from the position of the candle; and on my inquiring of the attendant, I found that he also had seen what he termed "fire come out of his mouth." I made a post-mortem examination of the body, for the benefit of all the lorers of the "fire-water" on the estate, and lectured them as severely as $I$ could, stating what $I$ expected to find in a man of such habits-that is, disease of the stomach, enlarged nutmeg-liver, and the lungs affected. These proved to be the appearances.

I remain, Sir, yours most respectfully,

Union Hall Estate, Trinidad, July 19th, 1845. WM. Hugains, M.D.

\section{TOILS, RESPONSIBILITY, AND REWARDS OF SUR- GEONS PRACTISING IN COUNTRY DISTRICTS.}

I SPENT two years at the hospitals, attending lectures on medicine, surgery, and midwifery; and, at the age of 22, passed my examination at the College, and became a member of that body. A small share of a country practice was immediately offered me, by a surgeon who had known me from boyhood, and which $\mathrm{I}$ accepted, although it was not likely to produce me more than 50l. per annum; but this was my only resource, for I had tried in vain for the situation of an assistant in London.

The town in which I now began my medical career contained about eight or nine thousand inhabitants, and several populous villages were situated within a few miles of the place; and there were barracks for one or two troops of horse-artillery, the medical attendance upon which was generally given to one of the resident surgeons. The practice depended, in a great measure, on midwifery, the fee for attendance rarely exceeding 10s. $6 \mathrm{~d}$.; there were three parishes contracted for at $20 l$. each; surgical and obstetrical cases being paid for extra, at low charges.

For ten years I continued in partnership with the founder of this practice, and by incessant labour increased the returns from $250 l$. to 7007 . per annum; attending myself from 200 to 300 cases of midwifery annually. Frequently have $I$ been up for six or seven nights in succession; an occasional hour's sleep in my clothes being the only repose $\mathrm{I}$ could obtain. The death of $\mathrm{my}$ partner about this time put me in possession of the entire emoluments, with the exception of $100 l$. annuity to the widow for a stipulated term of years.

My reputation now stood high; and by degrees my practice included all the principal families in the town and neighbourhood. and my returns exceeded 2000l. per annum; but this amount was made up of bills which would scarcely average more than 37 . or $4 l$. each, including the attendance on a military hospital, and on six large parishes.

To carry on such a practice, spread over an area of from thirty to forty miles in circumference, several assistants and apprentices, as well as horses, were necessary, for my daily list of patients, during the sickly seasons, often amounted to from sixty to one hundred cases.

The incessant toil and anxiety, and the want of sufficient sleep, which these duties involved, began seriously to affect my health; and after thirty years of unremitting labour $I$ was compelled to dispose of the practice, and seek the suburbs of some large town, where my experience and reputation might be likely to obtain for me a small income with but little exertion. For although my practice had for many years been very extensive, and the returns considerable, the attendant expenses (of assistants, horses, drugs, \&c.) swallowed up at least two-thirds of the receipts; and a bare support for my family only remained.

During this long period I was called upon to perform almost all the great operations in surgery, often suldenly, and without the possibility of obtaining the aid or sanction of another practitioner. Frequently have I had to perform the minor amputations of the extremities, with no assistance except what a neighbouring peasant or casual by-stander could afford.

As an accoucheur, my practice, as already stated, was very great; and, of course, many difficult and dangerous labours fell to my lot; oftentimes under circamstances the most distressing, from the abject poverty of the patients, and the next to impossibility of obtaining for them the necessaries of life. London PRACTICE is CHILD's PIAX compared with the arduous duties of the country practitioner. The responsibility of the most difficult and serious operations often rests solely upon himself; and he may be called upon at the very moment when, exhausted by previous fatigue, he is the least fitted for the task. I will illustrate this assertion by the following case, which is but one of many that occurred to me:-

On a miserable afternoon in October, after having been up 